\title{
An Innovative Series of Layered Nanostructured Aminoalkylsilica Hybrid Material
}

\author{
Carolina M. da Trindade, ${ }^{a}$ Gabriela C. Stoll, ${ }^{a}$ Altair S. Pereira, ${ }^{b}$ \\ Tania M. H. Costa ${ }^{a}$ and Edilson V. Benvenutti $* a$
}

\author{
${ }^{a}$ Instituto de Química, Universidade Federal do Rio Grande do Sul, CP 15003, 91501-970 Porto Alegre-RS, Brazil \\ ${ }^{b}$ Instituto de Física e Escola de Engenharia, Universidade Federal do Rio Grande do Sul, \\ CP 15015, 91501-970 Porto Alegre-RS, Brazil
}

\begin{abstract}
Uma nova série de amostras de material híbrido à base de sílica, contendo o grupo catiônico amoniopropil ligado na forma pendente, foi obtida usando-se o método sol-gel de síntese, variandose a razão molar entre o precursor inorgânico e o precursor orgânico. A análise termogravimétrica mostrou que as amostras são termicamente estáveis até $260{ }^{\circ} \mathrm{C}$. Os resultados obtidos por difratometria de raios $X$, microscopia eletrônica de transmissão, ressonância magnética nuclear de ${ }^{29} \mathrm{Si}$ e análise elementar são compatíveis com o modelo estrutural de camadas de silsesquioxano com distâncias basais de até 5,4 nm, contendo sílica amorfa no espaço entre as camadas.
\end{abstract}

An innovative series of silica-based hybrid materials containing pendant cationic ammoniumpropyl groups was obtained using the sol-gel method, by varying the molar ratio of the inorganic and organic precursors. Thermogravimetric analysis showed that samples were thermally stable up to $260^{\circ} \mathrm{C}$. Results obtained by X-ray diffractometry, transmission electron microscopy, ${ }^{29} \mathrm{Si}$ nuclear magnetic resonance and elemental analysis were compatible with a silsesquioxane layered structural model showing basal distances up to $5.4 \mathrm{~nm}$, containing amorphous silica in the interlayer space.

Keywords: nanostructured materials, layered hybrid materials, silsesquioxanes

\section{Introduction}

The development of organic-inorganic silica-based hybrid materials has received growing attention in the last decades. These materials present characteristics of the individual components as well as new unexpected properties. ${ }^{1-6} \mathrm{~A}$ satisfactory method to obtain these hybrid materials is the sol-gel synthesis, which allows dispersion of the components in nano or molecular scale, combining their physicochemical properties or producing new ones. Among this ensemble, the self-organized silica-based hybrid materials are very promising, because a great quantity of novel materials with attractive properties can be obtained..$^{7-12}$ They can be prepared using proper organosilane precursors presenting two or more polycondensation points, which are gelified together with an inorganic alkylorthosilicate precursor. The self-organization of these hybrid materials is imposed by the rigidity of the organic groups chemically bonded in a bridged way to the inorganic moiety. ${ }^{11-15}$

*e-mail: ebenvenutti@gmail.com
In recent times it was demonstrated that self-organized materials can also be obtained using bridging charged organic groups. ${ }^{16,17}$ It is important to point out that the selforganization in silica-based hybrid material has always been associated with the presence of bridging organic groups. Up to the present time, as far as we know, the synthesis of self-organized silica-based hybrid materials containing pendant organic groups has not been reported.

Another kind of hybrid materials can be obtained by gelation of organosilanes without addition of alkylorthosilicate inorganic precursors. These materials, called silsesquioxanes, have elevated organic content and can also present self-organization properties. Among them, the polyhedral oligomeric silsesquioxane (POSS) compounds, which have a functionalized silicon oxygen core, can act as robust nanometer sized building blocks for the preparation of new materials. ${ }^{18-21}$

More recently, it was reported that layered structures in silsesquioxanes containing charged pendant organic groups can be prepared using aminopropyltrimethoxysilane as precursor reagent, in very acid 
medium. ${ }^{22,23}$ The resulting product is a water soluble and viscous liquid of difficult handling. An alternative to prepare easy handling materials is the crystallization in acetone or the lyophilization process, in dry conditions. ${ }^{22,23}$ Even so, the material does not seem to have mechanical resistance to manipulation in open ambient condition. In the present work, to overcome this difficulty and to increase the possibility of applications for this kind of materials as stable two dimensional nanospaces for chemical processes, ${ }^{24-28}$ we have obtained a sample series of hybrid layered materials with the cationic ammoniumpropyl group and containing different amounts of inorganic component to improve the handling possibilities.

\section{Experimental}

\section{Synthesis of the hybrid material}

A solution containing 3-aminopropyltrimethoxysilane (APTMS) and hydrochloric acid $1 \mathrm{~mol} \mathrm{~L}^{-1}$, in the molar ratio of 1:3, APTMS/HCl, was stirred for $1 \mathrm{~h}$ at room temperature. Afterwards this solution was concentrated under stirring and heating $\left(150^{\circ} \mathrm{C}\right)$ for nearly $3 \mathrm{~h}$. The resulting product was the protonated organic precursor for the hybrid material synthesis, 3-ammoniumpropyl chloride silsesquioxane, called, from now on, APClsilsesquioxane. A schematic representation of this synthesis is shown in Figure 1.
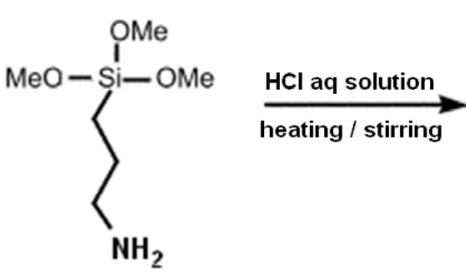

3-aminopropyltrimethoxysilane

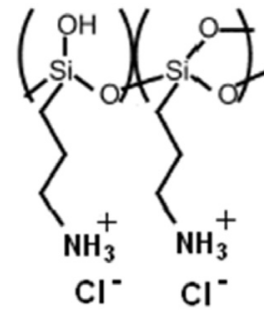

APCl-silsesquioxane
Figure 1. Schematic representation of the APCl-silsesquioxane synthesis.

The hybrid material sample series was obtained by gelation reactions of the protonated organic precursor APCl-silsesquioxane $(1.1 \mathrm{~g})$ with tetraethylorthosilicate (TEOS). The reactions were catalyzed by hydrofluoric acid (40\%, 2 drops). The different molar ratios of the organic and inorganic precursors are specified in Table 1.

The solutions were left to gelate for 15 days at ambient conditions, just covered, without sealing. Subsequently, the resulting product was heated in an oven at $60^{\circ} \mathrm{C}$ for drying and improving self-organization.
Table 1. Synthesis conditions for hybrid samples

\begin{tabular}{lccccc}
\hline Sample & $\begin{array}{c}\text { \% molar } \\
\text { inorganic }^{\mathrm{a}}\end{array}$ & $\begin{array}{c}\text { TEOS / ORG } \\
\text { molar ratio }^{\mathrm{a}}\end{array}$ & $\begin{array}{c}\mathrm{TEOS} / \\
\mathrm{mL}\end{array}$ & $\begin{array}{c}\mathrm{H}_{2} \mathrm{O} / \\
\mathrm{mL}\end{array}$ & $\begin{array}{c}\mathrm{EtOH} / \\
\mathrm{mL}\end{array}$ \\
\hline S50 & 50 & $1 / 1$ & 1.7 & 5.1 & 3.5 \\
S57 & 57 & $1.4 / 1$ & 2.4 & 7.2 & 4.8 \\
S61 & 61 & $1.6 / 1$ & 2.7 & 8.1 & 5.5 \\
S64 & 64 & $1.8 / 1$ & 3.1 & 9.2 & 6.1 \\
S67 & 67 & $2 / 1$ & 3.4 & 10.2 & 6.8 \\
S75 & 75 & $3 / 1$ & 5.2 & 15.3 & 10.22 \\
\hline
\end{tabular}

${ }^{a}$ Quantity added in the synthesis; ${ }^{b}$ Considering ammoniumpropyl chloride group added.

\section{Powder X-ray diffractometry}

X-ray diffraction patterns of the powdered samples were obtained with a Siemens Diffractometer model D500 using $\mathrm{Cu} \mathrm{K}_{\alpha}$ as radiation source, $\lambda=0.15418 \mathrm{~nm}$. The analysis was conducted at the scanning speed of $2^{\circ} \min ^{-1}$. The basal distances were calculated using the Bragg equation.

\section{Transmission electron microscopy}

The images of the hybrid materials were obtained on a $200 \mathrm{keV}$ Jeol transmission electron microscope-JEM 2010. The powdered samples were dispersed in hexane using an ultrasonic bath and deposited on a carbon-copper grid.

\section{Elemental analyses}

Elemental analyses of the organic groups present in the hybrid material samples were carried out in duplicate on a CHN Perkin Elmer M CHNS/O Analyzer, model 2400.

\section{$S i^{29}$ CP-MAS NMR spectroscopy}

Solid state ${ }^{29} \mathrm{Si}$ NMR spectroscopy was performed on a Bruker 300/P spectrometer using the MAS (Magic angle) technique with CP (Cross-polarization). The ${ }^{29} \mathrm{Si}$ NMR measurements were made utilizing pulse length of $2.5 \mathrm{~ms}$ and recycle delay of $1 \mathrm{~s}$.

\section{Thermogravimetric analyses}

The analyses were performed under nitrogen flow on a TA Instruments system, model TGA Q5000, with a heating rate of $20{ }^{\circ} \mathrm{C} \mathrm{min}^{-1}$ and from ambient temperature to $600{ }^{\circ} \mathrm{C}$. 


\section{Specific surface area}

The specific surface areas of the hybrid material samples were determined with previously degassed samples at $150{ }^{\circ} \mathrm{C}$ using the BET (Brunauer, Emmett and Teller) multipoint method, ${ }^{29}$ employing nitrogen adsorptiondesorption isotherms at liquid nitrogen boiling point. A homemade volumetric apparatus was used, connected to a vacuum line system provided with a turbo molecular Edward vacuum pump. Pressure measurements were made using a capillary $\mathrm{Hg}$ barometer.

\section{Results and Discussion}

In order to obtain the hybrid material sample series, the protonated organic precursor, 3-ammoniumpropyl chloride silsesquioxane (APCl-silsesquioxane), was synthesized following procedures already described. ${ }^{21,22}$ Different quantities of TEOS were added to this product, which was then left to form a gel first at room temperature and subsequently at $60{ }^{\circ} \mathrm{C}$. The resulting materials were transparent monoliths as shown in Figure 2.

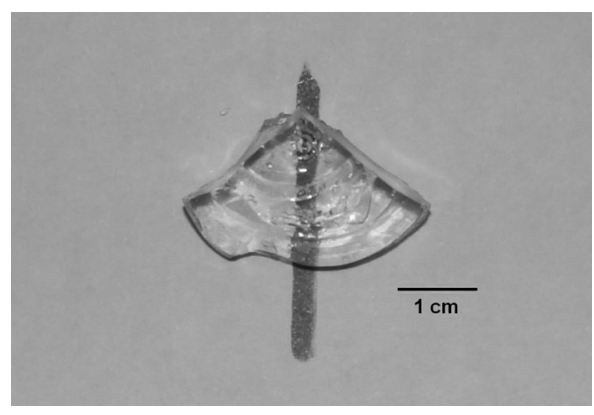

Figure 2. Picture of S67 hybrid sample.

In Figure 3, the X-ray diffraction patterns of the sample series of hybrid materials are presented. It is possible to observe that all patterns are dominated by two wide maxima: one located around $22^{\circ}$ and other in the region below $5^{\circ}$. The maximum around $22^{\circ}$ has been associated to the characteristic halo of amorphous silica, indicating the expressive presence of the inorganic component. The intense wide peak below $5^{\circ}$ is compatible with the expected diffraction pattern for layered silsesquioxane compounds. ${ }^{21,28}$ The intensity of this peak increases and its position shifts to lower angles with the increasing amount of the inorganic precursor, from S50 to S75 samples. The basal distances calculated for these peaks are in the range of 2.7 to $5.4 \mathrm{~nm}$ (Table 2).

The results of the nitrogen analyses of the hybrid sample series, expressed as mmol of aminopropyl group per gram of material, are shown in Table 2. A decrease in the organic

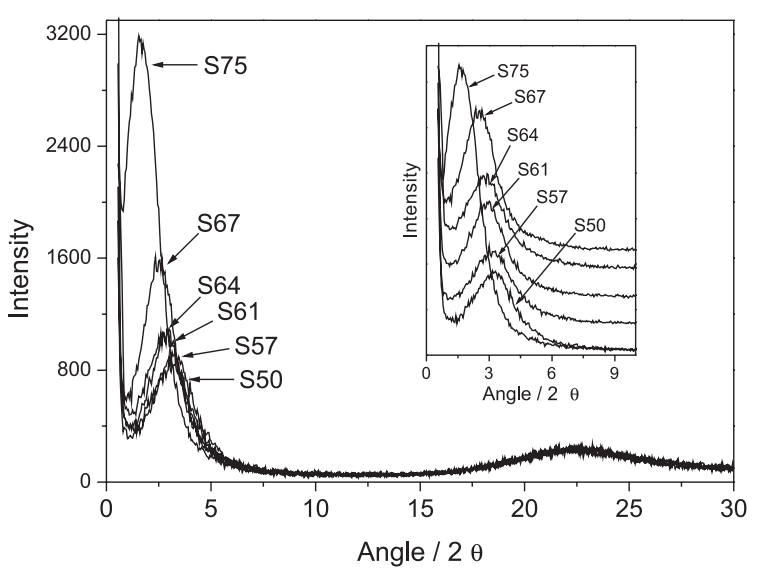

Figure 3. X-ray diffraction patterns of the series of hybrid material samples.

content can be observed from the S50 to the S75 sample, related to the increasing amount of the inorganic precursor added during the synthesis.

The water solubility results for all samples are also presented in Table 2. The increase in the amount of the inorganic component produces a decrease in the water solubility. This behavior has already been observed for hybrid materials containing charged organic pendant groups. ${ }^{30,31}$ The solubility was interpreted taking into account the ion-dipole interaction of the salt pendant groups with water molecules.

Figure 4 presents a typical thermogravimetric curve and its differential, showing two main weight losses. The first one occurred up to $150{ }^{\circ} \mathrm{C}$ and was assigned to adsorbed water. Another one, above $260^{\circ} \mathrm{C}$, was ascribed to organics removal. The elevated temperature for organics removal indicates the high thermal stability of all samples, where the organics are covalently bonded. ${ }^{32,33}$ The curves were very similar for all samples. The organic weight loss decreases from sample S50 to S75 with the increasing amount of inorganic precursor added (Table 2), in accordance with $\mathrm{CHN}$ elemental results, showing that it was possible to obtain a sample series with different inorganic/organic molar ratio. Regarding the water weight loss from room temperature to $150^{\circ} \mathrm{C}$, different types of behavior were observed. The first five samples, from S50 to S67, presented a weight loss ratio (organic groups/water) near three. This water was probably solvating the charged ammoniumpropyl groups. However, for the last sample, $S 75$, this ratio was only 0.47 , because this sample presented a very large water weight loss, indicating that there is another factor affecting the amount of water adsorbed. This factor could be the larger contribution of water adsorbed by the silica component.

For a better understanding of the TGA results, BET specific surface area measurements were performed for 
Table 2. Results of X-ray diffraction analysis, nitrogen elemental analysis, solubility results and thermogravimetric analysis of the hybrid sample series

\begin{tabular}{|c|c|c|c|c|c|}
\hline Sample & Basal distance / nm & $\begin{array}{l}\text { N elemental analysis / } \\
\left(\mathrm{mmol} \mathrm{g}^{-1}\right)\end{array}$ & $\begin{array}{l}\text { Water solubility / } \\
\qquad\left(\mathrm{g} \mathrm{L}^{-1}\right)\end{array}$ & $\begin{array}{c}\text { Weight loss } \% \text { / } \\
30-150{ }^{\circ} \mathrm{C}\end{array}$ & $\begin{array}{c}\text { Weight loss \% / } \\
150-430{ }^{\circ} \mathrm{C}\end{array}$ \\
\hline S50 & 2.7 & 3.3 & 14.7 & 10.57 & 27.69 \\
\hline S57 & 2.8 & 3.0 & 9.9 & 5.53 & 18.29 \\
\hline S61 & 3.0 & 2.8 & 9.7 & 6.14 & 17.91 \\
\hline S64 & 3.3 & 2.4 & 3.7 & 6.66 & 15.03 \\
\hline S67 & 3.5 & 2.4 & 2.2 & 4.13 & 15.48 \\
\hline S75 & 5.4 & 1.4 & 0.7 & 20.14 & 9.53 \\
\hline
\end{tabular}

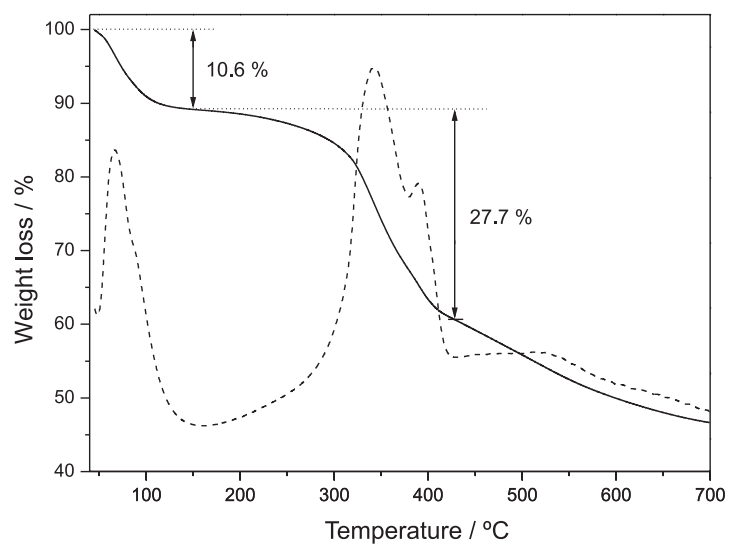

Figure 4. Thermogravimetric curve for the S50 sample.

the samples. The values obtained were $(550 \pm 25) \mathrm{m}^{2} \mathrm{~g}^{-1}$ for $\mathrm{S} 75$, while for all other samples the values were lower than $(60 \pm 10) \mathrm{m}^{2} \mathrm{~g}^{-1}$. The S75 was the only sample that presented a satisfactory $\mathrm{N}_{2}$ isotherm, typical of type 1 (microporous materials), ${ }^{34,35}$ possibly due to the presence of the hydrochloric acid used in the first step of the synthesis. This was interpreted taking into account the formation of an inorganic network, only in this sample, which presents a larger amount of silica. ${ }^{36}$ The surface of this silica moiety should be the reason for the high water adsorption value for this sample.

The ${ }^{29} \mathrm{Si}$ CP-MAS NMR spectra of the hybrid sample series are shown in Figure 5. There are two different regions with intense peaks: the first region, which presents chemical shifts between -50 and $-75 \mathrm{ppm}$, is due to $\mathrm{T}$ units, while the second region, with shifts between -85 and $-120 \mathrm{ppm}$, is due to $\mathrm{Q}$ units. According to the literature, $\mathrm{T}$ units are formed by silicon atoms bonded to carbon atoms of organic groups and $\mathrm{Q}$ units are silicon atoms of the siloxane and silanol groups. ${ }^{37-39}$

The peak assignments are presented in Table 3, and the relative abundance values of the $\mathrm{T}$ and $\mathrm{Q}$ species in the hybrid samples are presented in Table 4. It is clearly observed that the peak areas of $\mathrm{T}_{\text {total }}$ species decrease from sample S50 to S75, while an increase of the peak area of

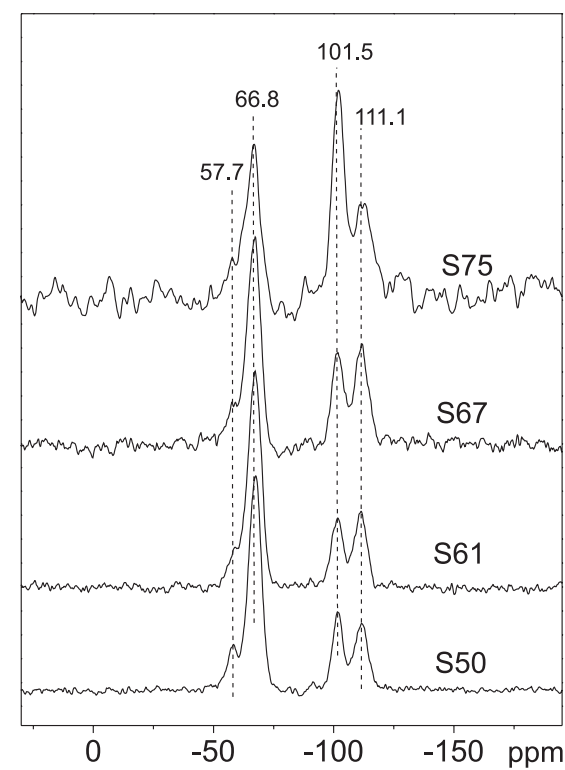

Figure 5. ${ }^{29} \mathrm{Si} \mathrm{CP}-\mathrm{MAS}$ NMR spectra of hybrid samples.

$\mathrm{Q}_{\text {toral }}$ species is observed. The $\mathrm{S} 75$ sample presents a marked fraction of silica, according to $\mathrm{CHN}$ and TGA results.

Table 3. Results of ${ }^{29} \mathrm{Si}$ CP-MAS NMR analysis

\begin{tabular}{lcc}
\hline Chemical shift/ppm & & Assignment \\
\hline ca. $-50^{\mathrm{a}}$ & $\mathrm{T}^{1}$ & $\mathrm{C}-\mathrm{Si}^{*}(\mathrm{OH})_{2}(\mathrm{OSi})$ \\
-57.7 & $\mathrm{~T}^{2}$ & $\left.\mathrm{C}-\mathrm{Si}^{*}(\mathrm{OH})_{(\mathrm{OSi}}\right)_{2}$ \\
-66.8 & $\mathrm{~T}^{3}$ & $\mathrm{C}-\mathrm{Si}^{*}(\mathrm{OSi})_{3}$ \\
$c a .-91^{\mathrm{a}}$ & $\mathrm{Q}^{2}$ & $(\mathrm{SiO})_{2} \mathrm{Si}^{*}(\mathrm{OH})_{2}$ \\
-101.5 & $\mathrm{Q}^{3}$ & $(\mathrm{SiO})_{3} \mathrm{Si}^{*}(\mathrm{OH})$ \\
-110.9 & $\mathrm{Q}^{4}$ & $(\mathrm{SiO})_{4} \mathrm{Si}^{*}$ \\
\hline
\end{tabular}

abtained from references 17 and 37.

Considering the $\mathrm{T}$ region in Figure 5, the abundance values listed in Table 4 showed a marked presence of the $\mathrm{T}^{3}$ species, higher than $80 \%$ for all samples. The $\mathrm{T}^{1}$ species were not observed, indicating the formation of a very crosslinked APCl-silsesquioxane moiety. For the $\mathrm{Q}$ region, assigned to silica, a comparable distribution of $\mathrm{Q}^{3}$ and $\mathrm{Q}^{4}$ 
Table 4. Relative abundance of $\mathrm{T}^{\mathrm{j}}$ and $\mathrm{Q}^{\mathrm{j}}$ species obtained from ${ }^{29} \mathrm{Si} \mathrm{CP}$ MAS NMR analysis

\begin{tabular}{lcccccc}
\hline \multicolumn{7}{c}{ Peak area / \% } \\
\hline Sample & $\mathrm{T}^{2}$ & $\mathrm{~T}^{3}$ & $\mathrm{Q}^{3}$ & $\mathrm{Q}^{4}$ & $\mathrm{~T}_{\text {total }}$ & $\mathrm{Q}_{\text {total }}$ \\
S50 & 14.6 & 85.4 & 51.2 & 48.8 & 63.1 & 36.9 \\
S61 & 12.8 & 87.2 & 45.2 & 54.8 & 64.2 & 33.8 \\
S67 & 12.5 & 87.5 & 46.1 & 53.9 & 59.4 & 40.6 \\
S75 & 19.2 & 80.8 & 61.7 & 38.3 & 35.9 & 64.1 \\
\hline
\end{tabular}

forms was observed for all samples, except for S75, that presents a major fraction of $\mathrm{Q}^{3}$, indicating the presence of a large quantity of silanol groups. This result is in accordance with the high BET surface area and high amount of adsorbed water obtained by TGA, for this sample.

Transmission electron microscopy (TEM) images of the S75 sample were obtained and a typical image is shown in Figure 6, where it is possible to observe a stacked plate-like structure for this sample. The inset presents the selected area electron diffraction pattern (SAED) of this plate, presenting a clear crystalline pattern. The hexagonal distribution of the spots was observed in all sample regions examined and it was already observed for ammoniumpropyl chloride silsesquioxane prepared with surfactant templates, without addition of TEOS..$^{40}$ Despite this finding cannot be conclusively associated to a hexagonal structure, this kind of pattern is compatible with a plate formed by six-member rings similar to silicates.

a)

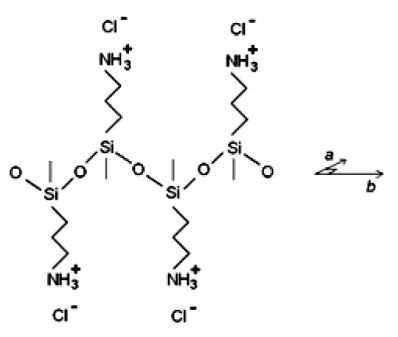

b)

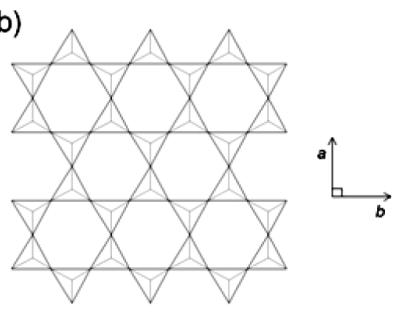

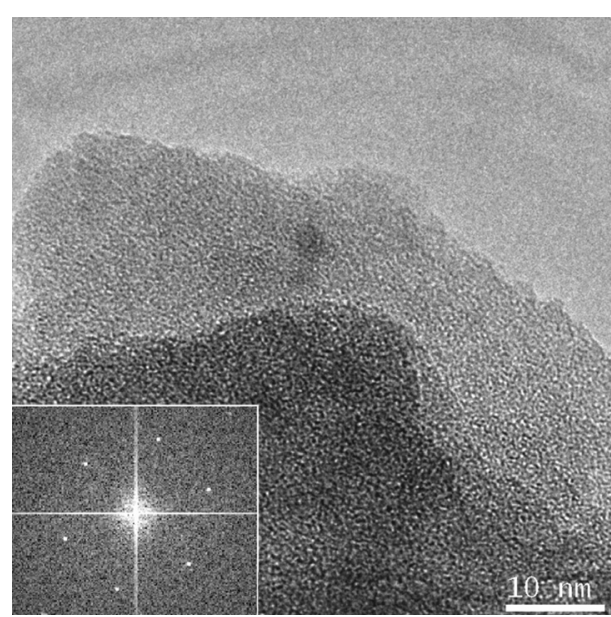

Figure 6. Transmission electron micrograph of the S75 sample. The inset shows the selected area electron diffraction pattern (SAED).

Considering all results, a model for the structure of the hybrid materials obtained in the present work is proposed. They are formed by two components. The first one is the layered APCl-silsesquioxane, represented in Figure 7a, forming a hexagonal, six-membered structure composed of silicon tetrahedra, illustrated in Figure 7b. This is in accordance with ${ }^{29} \mathrm{Si} \mathrm{NMR}$ results that showed a very crosslinked APClsilsesquioxane structure. The second component is silica formed during the gelation process, and it is located in the interlayer space, as shown in Figure 7c. This model is in accordance with the X-ray diffraction results, which gave basal distance values between 2.7 and $5.4 \mathrm{~nm}$. c)

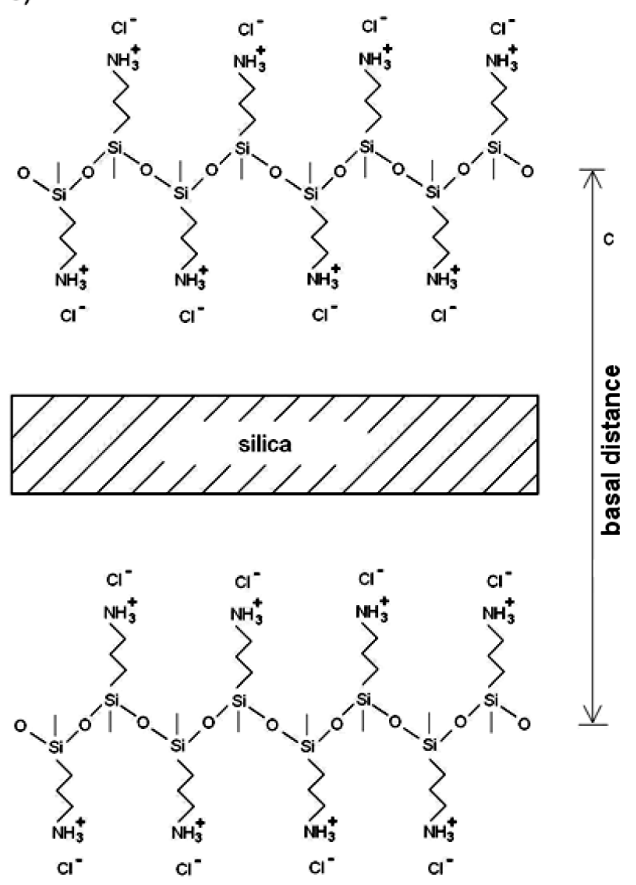

Figure 7. Schematic illustration of the proposed model for the layered aminoalkylsilica hybrid material. a) APCl-silsesquioxane; b) Top view of Si-O hexagonal layer of APCl-silsesquioxane; c) Vertical cross-section showing the layered structure of the hybrid material. 
The preparation of layered materials containing pendant organic groups with the basal distance related to the organic chain length has already been reported. ${ }^{28}$ In the present work, the basal distances are much larger than the aminopropyl groups. This large distance, which increases with the amount of inorganic precursor added, can be interpreted considering the formation of silica in the interlayer space.

The presence of distinct components, silica and APCl-silsesquioxane, instead of the formation of a hybrid material with molecular dispersion, can be explained considering that the silicon of the APCl-silsesquioxane was polycondensed in the first step of the synthesis, forming a viscous liquid. Additionally, the presence of the ammoniumalkyl groups hinders new polycondensation reactions, since they avoid the approximation of the inorganic precursor reactants, resulting in silica not covalently bonded to the APCl-silsesquioxane layer. This silica is inserted in the interlayer space during the heating gelation process, which envolves the melting of the sample. This experimental procedure is very important to produce the organized materials.

In the proposed model, silica is formed in the interlayer region, connected by Van der Waals and hydrogen bonds to the APCl-silsesquioxane layers. This results in a solid material with good handling properties, enlarging the possibility of applications. The silica located in the interlayer space is amorphous and can present variations in the thickness and adsorbed water. Consequently, there is not a regular stacking pattern along the $c$-axis represented in the Figure 7c. This model is in agreement with the $\mathrm{Si}^{29} \mathrm{NMR}$ results that showed very crosslinked APCl-silsesquioxane and silica moieties, predominantly $\mathrm{T}^{3}$ and $\mathrm{Q}^{4}$ species respectively, and can also explain the broad peaks observed in the X-ray diffraction patterns.

\section{Conclusions}

An innovative series of layered nanostructured hybrid material was obtained. All results are compatible with the proposed model, where the hybrid material is made of two distinct components: (i) a layer formed by ammoniumpropyl chloride silsesquioxane (APClsilsesquioxane) with hexagonal arrangement of silicon-like six-membered ring silicates; (ii) amorphous silica inserted in the interlayer space. ${ }^{29} \mathrm{Si}$ NMR results show that both organic and inorganic components are very crosslinked in distinct moieties, because $\mathrm{T}^{3}$ and $\mathrm{Q}^{4}$ species were predominantly observed. The presence of silica improves the handling properties of the products, decreases the solubility in relation to the silsesquioxane species and enlarges the possibilities of applications. The samples were thermally stable up to $260{ }^{\circ} \mathrm{C}$.

\section{Acknowledgments}

The authors thank CAPES and CNPq for grants and financial support. We also thank the CME-UFRGS for use of the Transmission Electron Microscopy (TEM) facilities.

\section{References}

1. Sanchez, C.; Boissière, C.; Grosso, D.; Laberty, C.; Nicole, L.; Chem. Mater. 2008, 20, 682.

2. Pilau, E. J.; Silva, R. G. C.; Jardim, I. C. E. S.; Augusto, F.; J. Braz. Chem. Soc. 2008, 19, 1136.

3. Hoffmann, F.; Cornelius, M.; Morell, J.; Froba, M.; J. Nanosci. Nanotechnol. 2008, 6, 265.

4. Gushikem, Y.; Benvenutti, E. V.; Kholin, Y. V.; Pure Appl. Chem. 2008, 80, 1593.

5. Arenas, L. T.; Simm, C. W.; Gushikem, Y. Dias, S. L. P.; Moro, C. C.; Costa, T. M. H.; Benvenutti, E. V.; J. Braz. Chem. Soc. 2007, 18, 886 .

6. Dunn, B.; Zink, J. I.; Acc. Chem. Res. 2007, 40, 747.

7. Fujita, S.; Inagaki, S.; Chem. Mater. 2008, 20, 891.

8. Luo, Y; Yang, P.; Lin, J.; Microporous Mesoporous Mater. 2008 , 111, 194.

9. Arenas, L. T.; Gay, D. S. F.; Moro, C. C. Dias, S. L. P.; Azambuja, D. S. Gushikem, Y; Costa, T. M. H.; Benvenutti, E. V.; Microporous Mesoporous Mater. 2008, 112, 273.

10. Okamoto, K.; Goto, Y.; Inagaki, S.; J. Mater. Chem. 2005, 15, 4136.

11. Cerveau, G.; Corriu, R. J. P.; Framery, E.; Lerouge, F.; Chem. Mater. 2004, 16, 3794.

12. Muramatsu, H.; Corriu, R. J. P.; Boury, B.; J. Am. Chem. Soc. 2003, 125, 854.

13. Boury, B.; Ben, F.; Corriu, R. J. P.; Delord, P.; Nobili, M.; Chem. Mater. 2002, 14, 730.

14. Moreau, J. J. E.; Pichon, B. P.; Bied, C.; Man, M. W. C.; J. Mater. Chem. 2005, 15, 3929.

15. Alauzun, J.; Mehdi, A.; Mouawia, R.; Reyé, C.; Corriu, R. J. P.; J. Sol-Gel Sci. Technol. 2008, 46, 383.

16. Arenas, L. T.; Dias, S. L. P.; Moro, C. C.; Costa, T. M. H.; Benvenutti, E. V.; Lucho, A. M. S.; Gushikem, Y.; J. Colloid Interface Sci. 2006, 297, 244.

17. Arenas, L. T.; Pinheiro, A. C.; Ferreira, J. D.; Livotto, P. R.; Pereira, V. P.; Gallas, M. R.; Gushikem, Y.; Costa, T. M. H.; Benvenutti, E. V.; J. Colloid Interface Sci. 2008, 318, 96.

18. Park, E. S.; Ro, H. W.; Nguyen, C. V.; Jaffe, R. L.; Yoon, D. Y.; Chem. Mater. 2008, 20, 1548.

19. Iacono, S. T.; Vij, A.; Grabow, W.; Smith, D. W.; Mabry, J. M.; Chem. Commun. 2007, 4992. 
20. Phillips, S. H.; Haddad, T. S.; Tomczak, S. J.; Curr. Opin. Solid State Mater. Sci. 2004, 8, 21.

21. Baney, R. H.; Itoh, M.; Sakakibara, A.; Suzuki, T.; Chem. Rev. 1995, 95, 1409.

22. Kaneko, Y.; Iyi, N.; Matsumoto, T.; Fujii, K.; Kurashima, K.; Fujita, T.; J. Mater. Chem. 2003, 13, 2058.

23. Kaneko, Y.; Iyi, N.; Kurashima, K.; Matsumoto,T.; Fujita, T.; Kitamura, K.; Chem. Mater. 2004, 16, 3417.

24. Xu, Z. P.; Stevenson, G. S.; Lu, C. Q.; Lu, G. Q.; Bartlett, P. F.; Gray, P. P.; J. Am. Chem. Soc. 2006, 128, 36.

25. Gardner, E.; Huntoon, K. M.; Pinnavaia, T. J.; Adv. Mater. 2001, $13,1263$.

26. Liu, Z. P.; Ma, R. Z.; Osada, M.; Iyi, N.; Ebina, Y.; Takada, K.; Sasaki, T.; J. Am. Chem. Soc. 2006, 128, 4872.

27. Darder, M.; López-Blanco, M.; Aranda, P.; Leroux, F.; RuizHitzky, E.; Chem. Mater. 2005, 17, 1969.

28. Yu, F. T.; Yao, K.; Shi, L. Y.; Wang, H. Z.; Fu, Y.; You, X. Q.; Chem. Mater. 2007, 19, 335.

29. Brunauer, S.; Emmett, P. H.; Teller, E.; J. Am. Chem. Soc. 1938, 60, 309.

30. Arenas, L. T.; Langaro, A.; Gushikem, Y.; Moro, C. C.; Benvenutti, E. V.; Costa, T. M. H.; J. Sol-Gel Sci. Technol. 2003, 28, 51.

31. Arenas, L. T.; Aguirre, T. A. S.; Langaro, A.; Gushikem, Y.; Benvenutti, E. V.; Costa, T. M. H.; Polymer 2003, 44, 5521.
32. Pavan, F. A.; Gobbi, S. A.; Costa, T. M. H.; Benvenutti, E. V.; J. Therm. Anal. Calorim. 2002, 68, 199.

33. Foschiera, J. L.; Pizzolato, T. M.; Benvenutti, E. V.; J. Braz. Chem. Soc. 2001, 12, 159.

34. Sing, K. S. W.; Everett, D. H.; Haul, R. A. W.; Moscou, L.; Pierotti, R. A.; Rouquérol, J.; Siemieniewska, T.; Pure Appl. Chem. 1985, 57, 603.

35. Gregg, S. J.; Sing, K. S. W.; Adsorption, Surface Area and Porosity, Academic Press: London, 1982, ch. 3, 4.

36. Azolin, D. R.; Moro, C. C.; Costa, T. M. H.; Benvenutti, E. V.; J. Non-Cryst. Solids 2004, 337, 201.

37. Sassi, Z.; Bureau, J. C.; Bakkali, A.; Vib. Spectrosc. 2002, 28, 299.

38. Oviatt, H. W.; Shea, K. J.; Small, J. H.; Chem. Mater. 1993, 5 , 943.

39. Dabrowski, A.; Barczak, M.; Stolyarchuk, N. V.; Melnyk, I. V.; Zub, Y. L.; Adsorption 2005, 11, 501.

40. Yao, K; Imai, Y.; Shi, L.; Dong, A.; Adachi, Y.; Nishikubo, K.; Abe, E.; Tateyama, H.; J. Colloid Interface Sci. 2005, 285, 259.

Received: November 17, 2008

Web Release Date: April 30, 2009 